\title{
Preoperative frailty affects postoperative complications, exercise capacity, and home discharge rates after surgical and transcatheter aortic valve replacement
}

\author{
Kodai Komaki ${ }^{1} \cdot$ Naofumi Yoshida $^{2} \cdot$ Seimi Satomi-Kobayashi ${ }^{2} \cdot$ Yasunori Tsuboi $^{1} \cdot$ Masato Ogawa $^{1,3}$. \\ Kumiko Wakida ${ }^{4} \cdot$ Takayoshi Toba $^{2} \cdot$ Hiroyuki Kawamori ${ }^{2} \cdot$ Hiromasa Otake $^{2} \cdot$ Atsushi Omura $^{5}$.

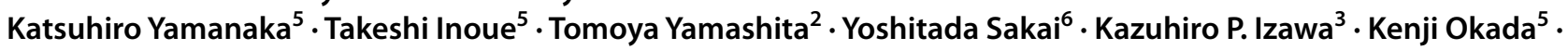 \\ Ken-ichi Hirata ${ }^{2}$
}

Received: 8 September 2020 / Accepted: 22 January 2021 / Published online: 22 February 2021

○) Springer Japan KK, part of Springer Nature 2021

\begin{abstract}
Assessment of frailty is important for risk stratification among the elderly with severe aortic stenosis (AS) when considering interventions such as surgical aortic valve replacement (SAVR) or transcatheter aortic valve replacement (TAVR). However, evidence of the impact of preoperative frailty on short-term postoperative outcomes or functional recovery is limited. This retrospective study included 234 consecutive patients with severe AS who underwent SAVR or TAVR at Kobe University Hospital between Dec 2013 and Dec 2019. Primary outcomes were postoperative complications, postoperative 6-min walking distance (6MWD), and home discharge rates. The mean age was $82 \pm 6.6$ years. There were 169 (SAVR: 80, TAVR: 89) and 65 (SAVR: 20, TAVR: 45) patients in the non-frail and frail groups, respectively $(p=0.02)$. The postoperative complication rates in the frail group were significantly higher than those in the non-frail group [30.8\% (SAVR: 35.0\%, TAVR: 28.9\%) vs. 10.7\% (SAVR: $15.0 \%$, TAVR: $6.7 \%$ ), $p<0.001$ ]. The home discharge rate in the non-frail group was significantly higher than that in the frail group [85.2\% (SAVR: $81.2 \%$, TAVR: $88.8 \%$ ) vs. $49.2 \%$ (SAVR: 55.0\%, TAVR: $46.7 \%$ ), $p<0.001$ ]. The postoperative 6MWD in the non-frail group was significantly longer than that in the frail group [299.3 $\pm 87.8 \mathrm{~m}$ (SAVR: $321.9 \pm 90.8 \mathrm{~m}$, TAVR: $281.1 \pm 81.3 \mathrm{~m}$ ) vs. $141.9 \pm 92.4 \mathrm{~m}$ (SAVR: $167.8 \pm 92.5 \mathrm{~m}$, TAVR: $131.6 \pm 91.3 \mathrm{~m}), p<0.001]$. The TAVR group did not show a decrease in the 6MWD after intervention, regardless of frailty. We report for the first time that preoperative frailty was strongly associated with postoperative complications, $6 \mathrm{MWD}$, and home discharge rates following both SAVR and TAVR. Preoperative frailty assessment may provide useful indications for planning better individualized therapeutic interventions and supporting comprehensive intensive care before and after interventions.
\end{abstract}

Keywords Frailty · Aortic stenosis · Surgical aortic valve replacement $\cdot$ Transcatheter aortic valve replacement $\cdot$ Exercise capacity

Seimi Satomi-Kobayashi

seimik@med.kobe-u.ac.jp

1 Division of Rehabilitation Medicine, Kobe University Hospital, Kobe, Japan

2 Division of Cardiovascular Medicine, Department of Internal Medicine, Kobe University Graduate School of Medicine, 7-5-2, Kusunoki-cho, Chuo-ku, Kobe, Hyogo 650-0017, Japan
3 Department of Public Health, Kobe University Graduate School of Health Sciences, Kobe, Japan

4 Department of Nutrition, Kobe University Hospital, Kobe, Japan

5 Division of Cardiovascular Surgery, Department of Surgery, Kobe University Graduate School of Medicine, Kobe, Japan

6 Division of Rehabilitation Medicine, Kobe University Graduate School of Medicine, Kobe, Japan 


\section{Introduction}

Aortic stenosis (AS) is a progressive age-related disease that develops over decades, increases the risk of heart failure, and is associated with poor survival $[1,2]$. As a result of the extension of life expectancy and increase in the prevalence of cardiovascular diseases associated with aging, the demand for AS management in the elderly population is growing. As there is a marked reduction in survival after the onset of symptoms, the options available include invasive interventions, surgical aortic valve replacement (SAVR), and transcatheter aortic valve replacement (TAVR) to improve symptoms and prolong survival $[3,4]$. As treatment methods such as surgical techniques and perioperative care have improved dramatically, perioperative mortality has decreased remarkably in recent years; nevertheless, postoperative functional decline has been a growing issue in patients undergoing surgery. Given these circumstances, frailty, which is a leading contributor to functional decline in older adults, is attracting considerable attention in the field of AS surgery. Frailty is of crucial importance, because it can affect postoperative daily physical capacity and home discharge rates, resulting in a decline in quality of life [5-9]. It is important to encourage early ambulation after intervention to maintain postoperative physical and cognitive function in daily activities and to support patients' discharge with multidisciplinary care [10]. However, little evidence exists on whether preoperative risk factors can predict postoperative physical activity.

A previous study reported a strong predictive ability of frailty status for 12 month mortality after TAVR [11]. Another large cohort study has shown that frailty is a major risk factor for death at 30 days and disability at 1 year following either SAVR or TAVR [12]. Considering this background, the current guidelines generally recommend assessment of frailty in patients with severe AS undergoing AVR [13]. However, evidence of the impact of preoperative frailty on short-term postoperative outcomes is limited. This single-center retrospective study sought to investigate whether preoperative frailty status was associated with postoperative short-term adverse events, postoperative physical activity such as $6 \mathrm{~min}$ walking distance (6MWD), the home discharge rate, length of intensive care unit stay, independent ambulation days, and length of hospital stay in Japanese patients with severe AS who underwent SAVR or TAVR. To understand the current status in detail and compare the differences in intervention, we analyzed the data of the SAVR and TAVR groups separately.

\section{Materials and methods}

\section{Patient population}

In this single-center retrospective study, we consecutively enrolled 236 patients aged $\geq 65$ years who had undergone SAVR or TAVR in accordance with the American College of Cardiology/American Heart Association (AHA/ACC) guidelines [14] from Dec 2013 to Dec 2019 at Kobe University Hospital. In Kobe University Hospital, TAVR was first performed in Oct 2015. Patients younger than 65 years were excluded as their etiologies of AS were not age-related degeneration; patients whose postoperative data could not be obtained because of hospital death were also excluded. This study was approved by the Ethics Committee of Kobe University (No. B190328), registered with the UMIN Clinical Trials Registry (trial registration No. UMIN000033173) and was performed according to the guidelines of the Declaration of Helsinki. All subjects provided informed consent to participate in this study via the opt-out method.

\section{Decision of intervention}

The definition of severe AS and treatment strategy were based on the AHA/ACC guidelines [15, 16]. Briefly, at the completion of the clinical evaluation of the patients, candidates for TAVR were further examined to assess the aortic valve and its surrounding structures as well as the vascular access route, using multi-detector computed tomography. The heart team, which comprised cardiac surgeons, cardiologists, and co-medical members, made a final decision regarding SAVR or TAVR in consideration of the risks and benefits for each intervention.

\section{Clinical characteristics of the patients}

Preoperative baseline characteristics, including age, sex, body mass index (BMI), single living, left ventricular ejection fraction, aortic valve area, aortic valve peak velocity, aortic valve mean pressure gradient, comorbidities, and medications, and interventional risk scores such as the European System for Cardiac Operative Risk Evaluation (EuroSCORE) II [17], Society of Thoracic Surgery (STS) risk score [18, 19], logistic EuroSCORE, and preoperative physical functions were extracted. The New York Heart Association functional classification was used to classify the extent of heart failure [20]. Diabetes mellitus was defined based on clinical history, hemoglobin A1c levels $\geq 6.5 \%$, and either a fasting plasma glucose (PG) level of $\geq 126 \mathrm{mg} /$ $\mathrm{dL}$ or PG level of $\geq 200 \mathrm{mg} / \mathrm{dL} 2 \mathrm{~h}$ after a $75 \mathrm{~g}$ oral glucose tolerance test [21]. Hypertension was defined as blood 
pressure $>140 / 90 \mathrm{mmHg}$ or the use of antihypertensive drugs. Dyslipidemia was defined as low-density lipoprotein cholesterol levels $>140 \mathrm{mg} / \mathrm{dL}$, triglyceride levels $>150 \mathrm{mg} /$ $\mathrm{dL}$, or use of antidyslipidemic drugs, according to the guidelines issued by the Japan Atherosclerosis Society [22].

\section{Measurement of preoperative frailty and exercise capacity}

We assessed preoperative frailty within 1 week prior to the intervention. We used frailty status as assessed using the Cardiovascular Health Study (CHS) frailty index [23]. Frailty was defined as a clinical syndrome in which three or more of the following criteria were present: unintentional weight loss (10 lbs in the past year), self-reported exhaustion, weakness (grip strength), slow walking speed, and low physical activity [23]. Handgrip strength was measured using a grip strength dynamometer (T.K.K.5401; Takei Scientific Instruments Co., Ltd., Niigata, Japan) [24]. Measurements were taken thrice for each hand while watching for a possible Valsalva effect. We used the highest value of right or left handgrip strength according to the standard protocol [24]. Walking speed was measured twice at the usual speed, as described elsewhere [24]. A $5 \mathrm{~m}$ section of the walkway was marked off by two lines, and space and time were allowed for acceleration and deceleration. The participants were allowed to use canes, but no assistance by a caregiver was permitted.

We used the 6MWD to assess exercise capacity. The 6MWD was measured within 1 week before SAVR or TAVR and approximately $14 \pm 7$ days after intervention.

\section{Postoperative parameters}

Postoperative clinical variables such as 6MWD, length of intensive care unit stay, independent ambulation days in the ward, length of hospital stay, postoperative complications, and home discharge rates were recorded. The 6MWD was measured again at approximately $14 \pm 7$ days after the intervention. Postoperative complications were defined as surgical site infections [25], acute kidney injury [26], stroke, prolonged ventilator management $(>48 \mathrm{~h})$, pacemaker implantation, and reoperation and were evaluated until 2 weeks after SAVR or TAVR. In TAVR, open surgery was also included as a postoperative complication. The judgment of patient's discharge was determined by the attending physician and heart team members according to the team's comprehensive judgment.

\section{Blood sampling}

Blood samples were collected after overnight fasting and were used to determine the levels of albumin, brain natriuretic peptide, hemoglobin, estimated glomerular filtration rate, hemoglobin A1c, aspartate aminotransferase, alanine aminotransferase, glutamyl transpeptidase, alkaline phosphatase, total bilirubin, C-reactive protein, total cholesterol, triglycerides, high-density lipoprotein cholesterol, and low-density lipoprotein cholesterol.

\section{Statistical analysis}

All data are presented as mean \pm standard deviation or proportions. Differences in continuous parameters among the four groups were calculated using one-way analysis of variance for parametric data. Tukey's test was performed as a post-hoc analysis for continuous variables. Non-parametric variables were compared using the Games-Howell test. Categorical variables are expressed as frequencies and percentages, and intergroup comparisons were analyzed using Fisher's exact test. Differences in continuous parameters between the two groups were calculated using a two-tailed paired $t$ test. For statistical correlation between two parameters, simple linear correlations were calculated using the method of least squares and by determining Pearson's correlation coefficient. To evaluate the differences and perioperative changes in the 6MWD, two-way repeated measures analysis of variance was used to compare the effects of frailty and intervention method (frail group vs. non-frail group, SAVR group vs. TAVR group) on functional recovery preand postoperatively.

The within-subject factor was time (time effect), and the between-subject factor was group (group effect). We analyzed the effect of time (before and after intervention), group (SAVR and TAVR), and time-group interaction.

Logistic regression analysis was used to examine the association between home discharge and each clinical characteristic. In this analysis, home discharge was used as the dependent variable, whereas the independent variables included frailty and other clinical characteristics. Univariate analysis was first performed, and all variables with $p<0.10$ were entered en bloc in the multivariate model, along with age, sex, and type of intervention as background variables. Analyses were performed using commercially available software (JMP version 11.0, SAS Institute). Values of $p<0.05$ were considered statistically significant.

\section{Results}

\section{Baseline patient characteristics}

Two hundred and thirty-six patients were considered eligible for inclusion. We did not extract any outcome of interest for two patients due to death. Finally, 234 patients with a mean age of $82.0 \pm 6.6$ years were the participants of the present 
study. The baseline characteristics, echocardiographic parameters, medications, and laboratory data are shown in Table 1. The patients were divided into the SAVR group $(n=100)$ and TAVR group $(n=134)$ according to the type of intervention. In all patients in the SAVR group, surgery was performed through median sternotomy using cardiopulmonary bypass with hypothermic circulatory arrest. All patients were selected for the biological valve, and none were selected for the mechanical valve. In the TAVR group, the procedure was performed under general anesthesia in 132 patients (98.5\%); nevertheless, local anesthesia was used in two patients $(1.5 \%)$ who had a history of severe interstitial pneumonia. We further divided the patients according to the presence of preoperative frailty in each group. The number of patients in each group was $80,20,89$, and 45 in the SAVR non-frail, SAVR frail, TAVR non-frail, and TAVR frail groups, respectively.

Patient age was significantly higher in the TAVR group than in the SAVR group $(85.5 \pm 4.2$ vs. $77.3 \pm 6.5, p<0.001)$. There was no significant difference in BMI between the SAVR and TAVR groups $\left(23.0 \pm 0.4\right.$ vs. $22.3 \pm 0.3 \mathrm{~kg} / \mathrm{m}^{2}$, $p=0.196)$. The ratio of women was higher in the TAVR group than in the SAVR group ( 73 vs. $51 \%, p<0.001$ ). Interestingly, the rate of single living was significantly lower in the SAVR group than in the TAVR group (17.0 vs. $36.7 \%$, $p=0.003)$. The TAVR group had lower albumin, hemoglobin, alanine aminotransferase, and high-density lipoprotein cholesterol levels than the SAVR group $(p<0.05$ for each).

There were no significant differences in AS severity with echocardiographic parameters such as aortic valve area determined by the continuity equation, AS peak jet velocity, mean transvalvular pressure gradient, and left ventricular ejection fraction among the four groups. While the mean age in the intra groups of SAVR was significantly different $(76.5 \pm 6.0$ in non-frail vs. $80.6 \pm 7.4$ in frail, $p=0.01$ ), the mean age in the intra groups of TAVR was almost similar $(85.5 \pm 3.7$ in non-frail vs. $85.6 \pm 5.0$ in frail, $p=1.00$ ).

We then analyzed the impact of frailty on patient characteristics in the SAVR and TAVR groups. The proportion of women was not statistically different in the intra-group analysis (SAVR, $47.5 \%$ in non-frail vs. $65.0 \%$ in frail; TAVR, $71.9 \%$ in non-frail vs. $75.6 \%$ in frail). The SAVR frail group tended to have a higher rate of single living than the SAVR non-frail group $(30.0 \%$ vs. $13.7, p=0.084)$. There was no significant difference in laboratory data between the SAVR non-frail and frail groups. On the other hand, the TAVR frail group had significantly lower albumin, hemoglobin, and high-density lipoprotein cholesterol levels than the TAVR non-frail group. In terms of medications, the frail SAVR and TAVR groups tended to take diuretics more frequently than the non-frail SAVR and TAVR groups. No significant differences in comorbidities were observed among the four groups.

The EuroSCORE II was not significantly different between the non-frail and frail groups. Therefore, we did not evaluate the logistic EuroSCORE and STS risk scores in the SAVR group. The EuroSCORE II in the TAVR frail group was significantly higher than that in the TAVR nonfrail group $(15.4 \pm 9.6$ vs. $11.6 \pm 6.7, p=0.006)$. Similarly, the logistic EuroSCORE and STS risk scores in the TAVR frail group were significantly higher than those in the TAVR non-frail group ( $p=0.001$ and $p=0.021$, respectively).

\section{Preoperative physical function}

The SAVR group had significantly higher physical function than the TAVR group, as assessed by grip strength, gait speed, and 6MWD $(p<0.001)$ (Table 1). The frail group had significantly lower physical function than the non-frail group in the SAVR and TAVR groups ( $p<0.001$ for each).

\section{Primary outcomes}

In the patients who underwent SAVR, postoperative complication rates in the frail group were significantly higher than those in the non-frail group (35.0 vs. $15.0 \%, p<0.041$ ). The distribution of the complications was as follows: two surgical site infections, three strokes, two prolonged ventilator management, seven pacemaker implantations, and four reoperations (Fig. 1a, b). In the TAVR group, the postoperative complication rate was significantly higher in the frail group than in the non-frail group ( 28.9 vs. $6.7 \%, p<0.001$ ). The distribution of the complications was: 1 acute kidney injuries, two strokes, 12 pacemaker implantations, and four reoperations (Fig. 1c, d).

Table 2 and Fig. 2 show a comparison of the 6MWD preand post-intervention. The 6MWD in the non-frail group was always better than that in the frail group, regardless of the type of intervention ( $p<0.001$ for each) (Fig. 2b, c). It is worth noting that patients in the TAVR group could maintain the 6MWD after the intervention (Fig. 2a, c). On the other hand, the postoperative 6MWD significantly decreased in patients who underwent SAVR (Fig. 2a, b). The decline in the 6MWD throughout the perioperative period did not show statistically significant differences between the non-frail and frail groups in the same intervention (interaction: SAVR: 0.541, and TAVR: 0.812) (Fig. 2b, c, Table 2). 


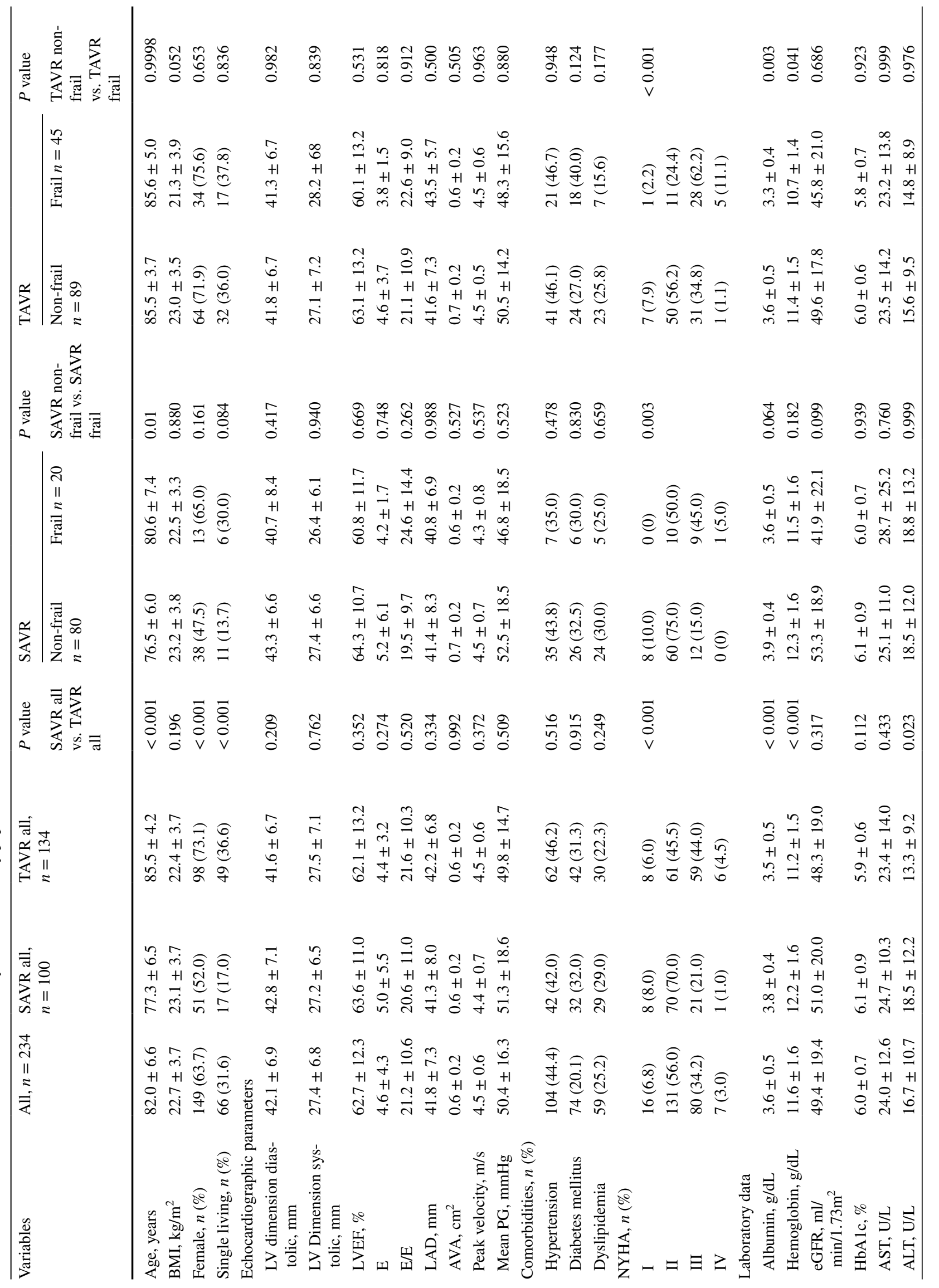




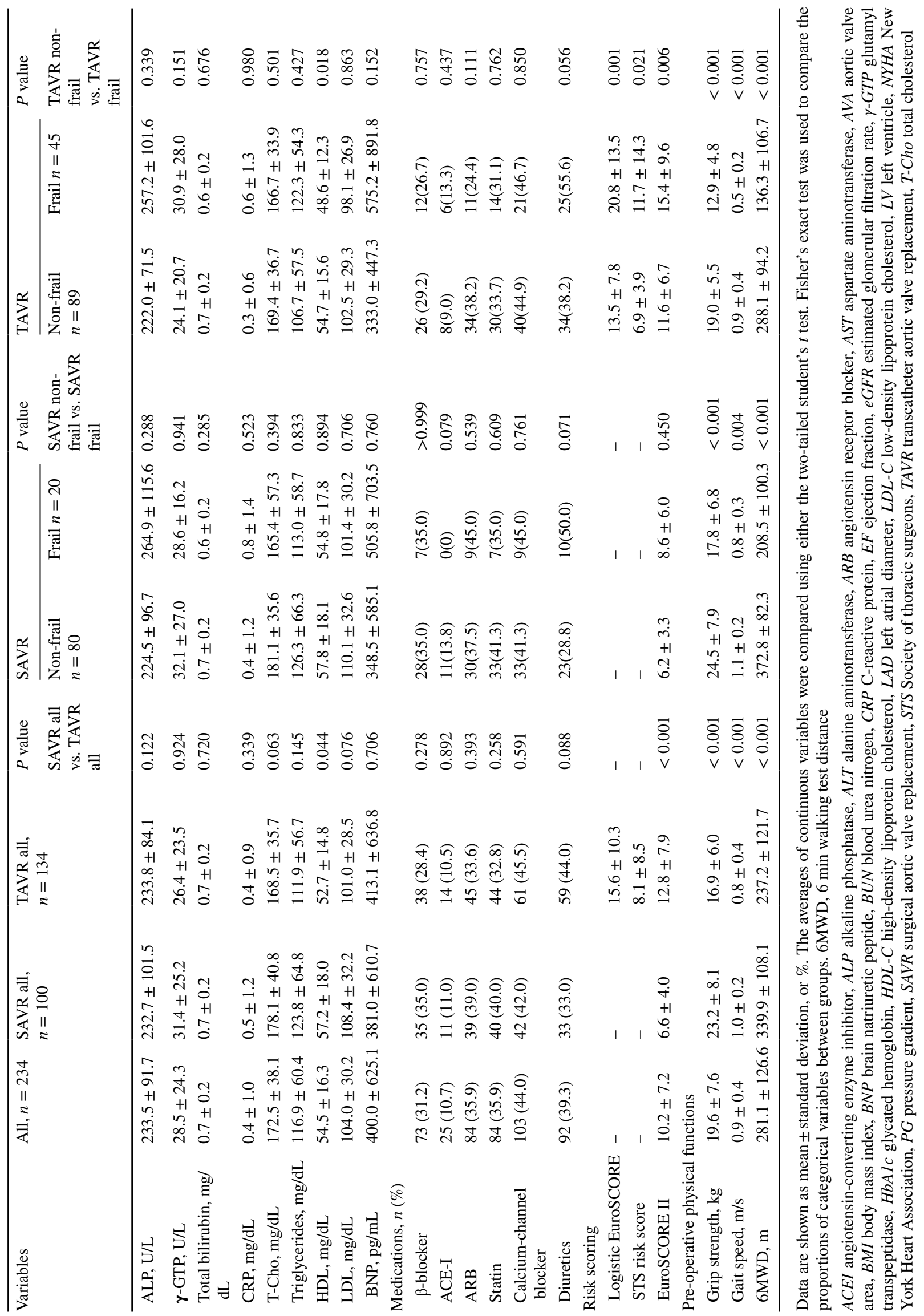


Fig. 1 Incidence of postoperative complications among four groups. Data are shown as percentages (\%). $A K I$ acute kidney injury, $P M I$ pacemaker implantation, $P V M$ prolonged ventilator management, $S A V R$ surgical aortic valve replacement, TAVR transcatheter aortic valve replacement

Table 2 Result of 6MWD of pre and post operation

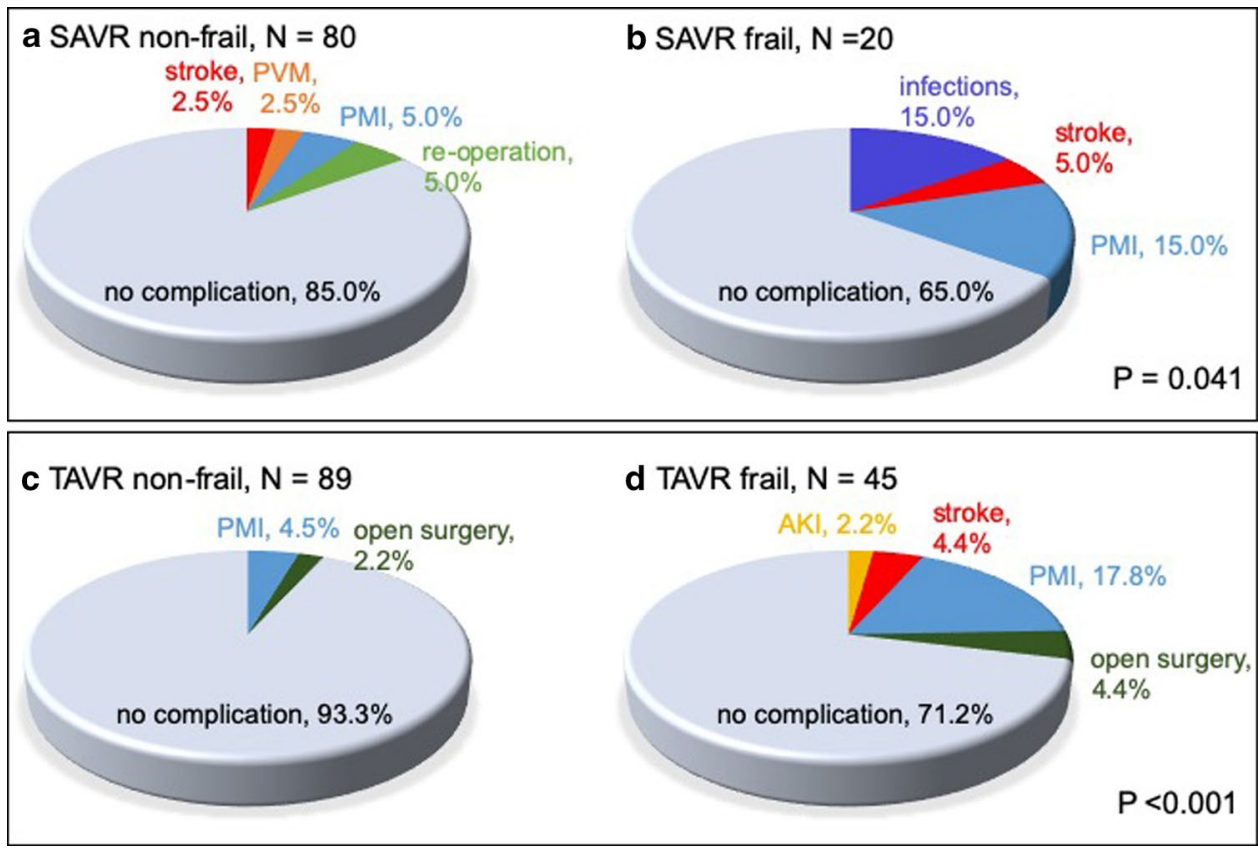

\begin{tabular}{llllll}
\hline Variables & Pre & Post & $p$ value $^{\mathrm{b}}$ & \multicolumn{2}{l}{ Interaction } \\
\cline { 5 - 6 } & & & \multicolumn{2}{l}{$F$ value $^{\text {value }^{\mathrm{c}}}$} \\
\hline All patients & & & & \\
SAVR & $339.9 \pm 108.1^{\mathrm{a}}$ & $291.1 \pm 109.8^{\mathrm{a}}$ & $<0.001$ & 27.84 & $<0.001$ \\
TAVR & $237.2 \pm 121.7$ & $230.9 \pm 110.3$ & 0.16 & - & - \\
SAVR & & & & 0.541 \\
Non-frail & $372.8 \pm 82.3^{\mathrm{a}}$ & $321.9 \pm 90.8^{\mathrm{a}}$ & $<0.001$ & 0.376 & - \\
Frail & $208.5 \pm 100.3$ & $167.8 \pm 92.5$ & $<0.001$ & - & 0.812 \\
TAVR & & & & & - \\
Non-frail & $288.1 \pm 94.2^{\mathrm{a}}$ & $281.1 \pm 81.3^{\mathrm{a}}$ & 0.202 & 0.057 & - \\
Frail & $136.3 \pm 106.7$ & $131.6 \pm 91.3$ & 0.537 & - & \\
\hline
\end{tabular}

6MWD, 6 min walking test distance

$S A V R$ surgical aortic valve replacement, TAVR transcatheter aortic valve replacement

${ }^{a}$ Significance level for the hypothesis of no group effect

${ }^{\mathrm{b}}$ Significance level for the hypothesis of time effect (pre vs. post in the same group)

${ }^{\mathrm{c}}$ Significance level for the hypothesis of no time $\times$ group effect a All patients. SAVR vs. TAVR

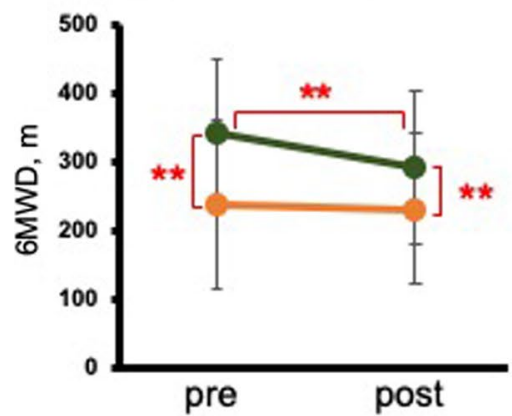

b SAVR. non-frail vs. frail

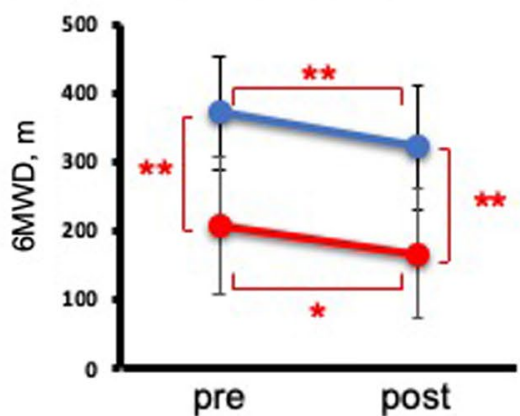

c TAVR. non-frail vs. frail

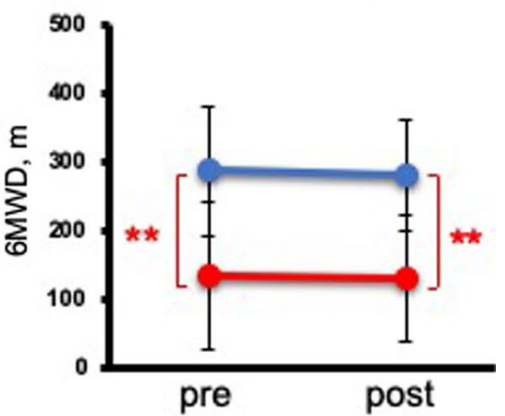

Fig. 2 Change in the pre- and postoperative 6MWD. 6MWD, 6 min walking distance; SAVR surgical aortic valve replacement, TAVR transcatheter aortic valve replacement $* p<0.01, * * p<0.001$ 
Home discharge rates of patients in the SAVR non-frail, SAVR frail, TAVR non-frail, and TAVR frail groups were 81.3, 55.0, 88.8, and 46.7\%, respectively (Fig. 3 ).

Home discharge rates in the non-frail group were significantly higher than those in the frail group, regardless of the type of intervention (SAVR, $p=0.014$; TAVR, $p<0.001$ ).

\section{Association between home discharge and variables}

The results of the logistic regression analysis of home discharge are shown in Table 3. After adjusting for all confounding factors, age $(p<0.001)$, single living $(p=0.016)$, and frailty (odds ratio: $0.131 ; 95 \%$ confidence interval $0.058-0.285 ; p<0.001)$ remained statistically significant predictors of home discharge.

\section{Additional outcomes}

The length of stay in the intensive care unit did not differ between the SAVR non-frail and frail groups (Fig. 4a). On the other hand, the TAVR frail group had a longer intensive care unit stay than the TAVR non-frail group (Fig. 4a). The frail group showed longer independent ambulation days in both the SAVR and TAVR groups (Fig. 4b). Postoperative hospital stay did not differ between the SAVR non-frail and frail groups, whereas the TAVR frail group showed a longer postoperative hospital stay than the TAVR non-frail group (Fig. 4c).
Fig. 3 Home discharge rate among four groups. Data are shown as percentages (\%). SAVR surgical aortic valve replacement, TAVR transcatheter aortic valve replacement
Table 3 Logistic regression model of home discharge
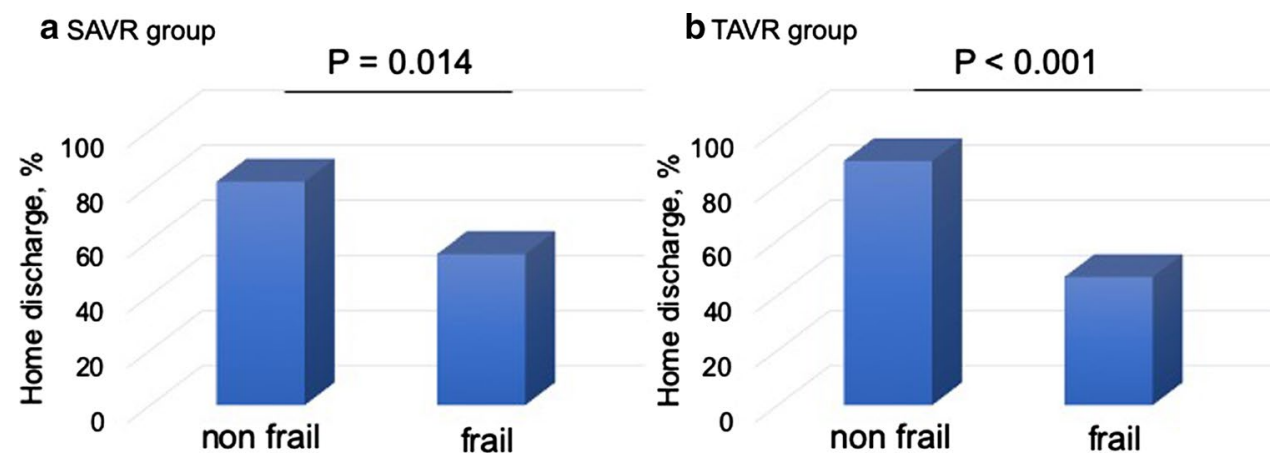

\begin{tabular}{llrlrr}
\hline Variable & Univariable & & Multivariable & \\
\cline { 2 - 3 } & OR $(95 \% \mathrm{CI})$ & $p$ value & & OR $(95 \%$ CI $)$ & $p$ value \\
\hline Age & $0.916(0.866-0.963)$ & $<0.001$ & & $0.895(0.829-0.963)$ & 0.003 \\
Sex, (ref. female) & $0.591(0.301-1.115)$ & 0.106 & & $1.087(0.463-2.521)$ & 0.846 \\
Intervention, (ref. SAVR) & $1.077(0.592-1.980)$ & 0.809 & & $0.382(0.136-1.046)$ & 0.061 \\
Albumin & $2.471(1.255-5.084)$ & 0.008 & & $1.276(0.326-2.040)$ & 0.603 \\
CRP & $0.762(0.594-0.946)$ & 0.013 & & $0.764(0.555-1.016)$ & 0.066 \\
Frail & $0.168(0.087-0.319)$ & $<0.001$ & & $0.131(0.058-0.285)$ & $<0.001$ \\
Single living & $0.401(0.214-0.752)$ & 0.004 & & $0.378(0.169-0.831)$ & 0.016 \\
\hline
\end{tabular}

$C R P$ C-reactive protein, $C I$ confidence interval, $O R$ odds ratio, $S A V R$ surgical aortic valve replacement

a ICU stay

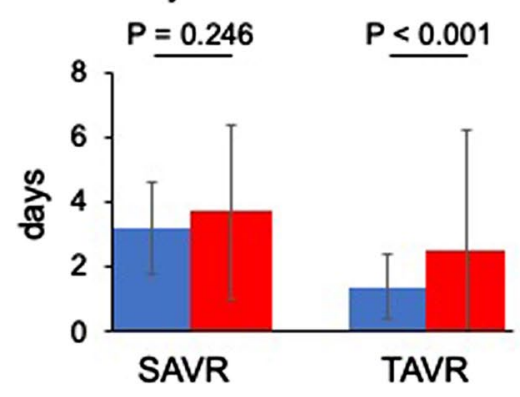

b Ambulation independent day

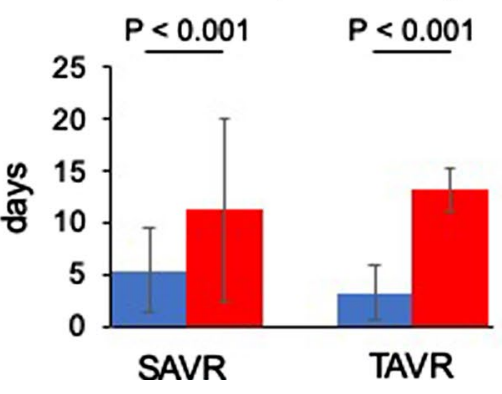

c Post operative hospital stay

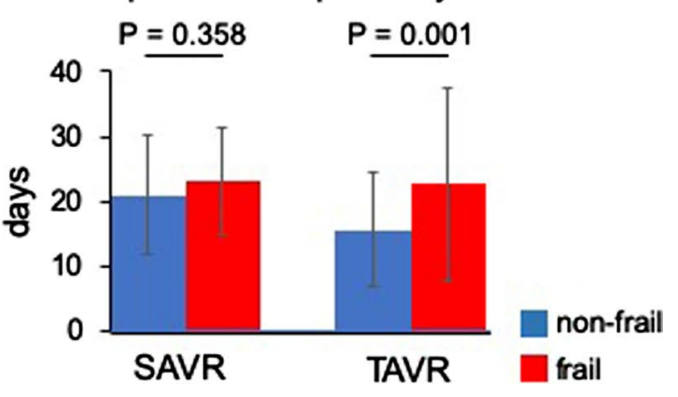

Fig. 4 Data of additional outcomes. ICU intensive care unit, SAVR surgical aortic valve replacement, TAVR transcatheter aortic valve replacement 


\section{Discussion}

To the best of our knowledge, this is the first report to clearly indicate a significant association between preoperative frailty status as assessed using the CHS Frailty Index and postoperative physical activity in Japanese patients with severe AS who underwent SAVR or TAVR. The main findings of this study are as follows: frailty was an independent risk factor for postoperative complications and the difficulty of home discharge in both the SAVR and TAVR groups and the 6MWD decreased significantly after intervention in patients in the SAVR group; however, there was no significant reduction in 6MWD in patients who underwent TAVR. Our findings suggest that preoperative assessment of frailty may be crucial for predicting shortterm postoperative outcomes of both SAVR and TAVR.

In previous studies, frailty was common in patients undergoing cardiac surgery and increased postoperative complications [27, 28]. Our results were similar to those of previous reports, but the incidence of complications was found to vary slightly from study to study. In part, various methods of assessing frailty status can contribute to the observed discrepancy. The SAVR group had a higher incidence of surgical site infection than the TAVR group possibly due to surgical invasion such as sternotomy. The TAVR non-frail group showed a low complication rate; it is one of the benefits of TAVR, in that it requires minimally invasive procedures. Nevertheless, the frail group showed a non-negligible incidence of complications in both intervention groups, such as stroke and the need for pacemaker implantation. Therefore, we should carefully weigh the benefits against the risks when we recommend SAVR or TAVR for frail patients.

Logistic regression analysis showed no significant difference in postoperative complications for each frailty parameter for both the SAVR and TAVR groups. On the other hand, weakness had the greatest contribution to the home discharge rate in the SAVR group (odds ratio, 0.29; 95\% CI, 0.088-0.886; $p=0.029)$. Similarly, weakness had the greatest contribution to the home discharge rate in the TAVR group (odds ratio, 0.37; 95\% CI, 0.143-0.965; $p=0.041)$. Collectively, our data suggest that frailty, especially weakness, plays an important role in postoperative outcomes. However, we believe that frailty should be assessed comprehensively by a combination of parameters, rather than just a single parameter.

A prior study from the United States showed that the rates of discharge to rehabilitation facilities increased with increasing frailty [29]. Although body weight, BMI, and the hospital and healthcare environment in the previous study were completely different from those in the current study due to county differences, the results of our study (the home discharge rate was higher in the non-frail group than in the frail group) were consistent with those of the previous study. One of the reasons for the lower home discharge rates in the frail group may be attributed to not only lower physical function but also less physiological reserve in the frail group. In other words, the patients assessed as frail using the CHS frailty index, who have a low nutritional status, low physical activity, and muscle weakness, would have a high frequency of complications and, therefore, have a long hospital stay and require rehabilitation transfer to improve nutrition and activities of daily living. In contemporary TAVR, discharge disposition significantly affects the 1 year risk of cardiovascular death and stroke, and even after adjustment for recorded baseline differences [8], preoperative assessment of frailty is of crucial importance for both SAVR and TAVR. The aim of home discharge is to improve patient prognosis.

In previous studies, the 6MWD was found useful in identifying frailty and those in transition to frailty [30, 31]. Earlier studies in elderly patients with heart failure reported that the 6MWD correlated with frailty and was associated with mortality [32]. Similarly, in this study, the 6MWD was significantly lower in the frail group. Preoperative and postoperative exercise-based cardiac rehabilitation have been reported to improve the 6MWD [33-37]. In addition, comprehensive cardiac rehabilitation may help prevent, reverse, and reduce the severity of frailty and improve the prognosis of frail patients with valvular disease following surgery or intervention [38]. Therefore, for frail patients with a low preoperative 6MWD, exercise-based cardiac rehabilitation is strongly recommended after relief from severe aortic stenosis.

The SAVR group showed a significant decrease in the 6MWD after surgery, whereas the TAVR group did not. To our knowledge, there have been no reports on the change in the 6MWD before and after SAVR or TAVR. We previously reported that the 6MWD decreased about 20\% during the perioperative period in patients undergoing valvular surgery, which were regarded to be due to postoperative inflammation and catabolic responses [39]. TAVR, which is a less invasive intervention for AS, could maintain the exercise capacity of patients during the perioperative period. Therefore, the assessment of preoperative exercise capacity and frailty is considered to be of great importance in the decision on the intervention.

In our study, the postoperative hospital stay was long. First, the length of hospital stay after SAVR and TAVR is relatively long in Japan compared to that in other Western countries. Furthermore, the patients who underwent SAVR in the present study were older than those in recent clinical trials. In addition, the patients included in our study had severe symptoms of heart failure before surgery, as indicated by the high preoperative brain natriuretic peptide levels. 
These factors could lead to prolonged postoperative management of heart failure and the time required for postoperative rehabilitation, resulting in a prolonged hospital stay.

To treat in the frailty of patients with AS and improve their prognosis, early postoperative exercise therapy and comprehensive multi-disciplinary cardiac rehabilitation, which is available even before surgery, are desirable. Among the comprehensive multi-disciplinary interventions, we consider that preoperative nutritional intervention is effective in preventing postoperative complications.

Approximately $21.3 \%$ of the global population will be 60 years or older by 2050 [40] and the number of elderly patients with AS would keep increasing. From a future clinical perspective, our results strongly support the idea that multifactorial intervention is essential to prevent the progression of frailty in patients with AS.

\section{Study limitations}

This study has several limitations. First, this was a retrospective, single-center study with a relatively small sample size. Larger prospective multi-center trials could reveal the current frailty status of Japanese patients with severe AS undergoing SAVR or TAVR. Further studies are needed to increase the sample size and perform a sub-analysis to investigate which parameters of frailty affect postoperative outcomes. Second, the results might be biased by the differences in baseline characteristics between the patients undergoing TAVR and SAVR. Third, as this was a clinical study, we were unable to clarify the reason for decreased postoperative physical activity in frail patients. We hope to explore the pathophysiological mechanisms underlying frailty in the future based on the results of this study.

\section{Conclusions}

Our results indicate that preoperative frailty status was associated with postoperative complications in patients with severe AS who underwent SAVR or TAVR. Preoperative frailty assessment may provide useful indications for planning better individualized therapeutic interventions and supporting comprehensive intensive care for vulnerable patients with AS following interventions.

Acknowledgements We thank all the patients for their participation in this study and our colleagues at our institution for their contribution to the medical care of the patients.

\section{Compliance with ethical standards}

Conflict of interest The authors have no conflicts of interest relevant to this study to declare.

\section{References}

1. Lindman BR, Clavel M-A, Mathieu P, Iung B, Lancellotti P, Otto CM, Pibarot P (2016) Calcific aortic stenosis. Nat Rev Dis Primers 2:16006

2. Iung B, Baron G, Butchart EG, Delahaye F, Gohlke-Bärwolf C, Levang OW, Tornos P, Vanoverschelde J-L, Vermeer F, Boersma E, Ravaud P, Vahanian A (2003) A prospective survey of patients with valvular heart disease in Europe. The Euro Heart Survey on valvular heart disease. Eur Heart J 24:1231-1243

3. Leon MB, Smith CR, Mack M, Miller DC, Moses JW, Svensson LG, Tuzcu EM, Webb JG, Fontana GP, Makkar RR, Brown DL, Block PC, Guyton RA, Pichard AD, Bavaria JE, Herrmann HC, Douglas PS, Petersen JL, Akin JJ, Anderson WN, Wang D, Pocock S (2010) Transcatheter aortic-valve implantation for aortic stenosis in patients who cannot undergo surgery. N Engl J Med 363:1597-1607

4. Leon MB, Smith CR, Mack MJ, Makkar RR, Svensson LG, Kodali SK, Thourani VH, Tuzcu EM, Miller DC, Herrmann HC, Doshi D, Cohen DJ, Pichard AD, Kapadia S, Dewey T, Babaliaros V, Szeto WY, Williams MR, Kereiakes D, Zajarias A, Greason KL, Whisenant BK, Hodson RW, Moses JW, Trento A, Brown DL, Fearon WF, Pibarot P, Hahn RT, Jaber WA, Anderson WN, Alu MC, Webb JG (2016) Transcatheter or surgical aortic-valve replacement in intermediate-risk patients. $\mathrm{N}$ Engl J Med 374:1609-1620

5. Grimaldi A, Figini F, Maisano F, Montorfano M, Chieffo A, Latib A, Pappalardo F, Spagnolo P, Cioni M, Vermi AC, Ferrarello S, Piraino D, Cammalleri V, Ammirati E, Sacco FM, Arendar I, Collu E, La Canna G, Alfieri O, Colombo A (2013) Clinical outcome and quality of life in octogenarians following transcatheter aortic valve implantation (TAVI) for symptomatic aortic stenosis. Int J Cardiol 168:281-286

6. Arnold SV, Reynolds MR, Lei Y, Magnuson EA, Kirtane AJ, Kodali SK, Zajarias A, Thourani VH, Green P, Rodés-Cabau J, Beohar N, Mack MJ, Leon MB, Cohen DJ (2014) Predictors of poor outcomes after transcatheter aortic valve replacement. Circulation 129:2682-2690

7. Hiltrop N, Belmans A, Claes M, Hornikx M, Peeters B, Flamaing J, Adriaenssens T, De Praetere H, Herregods M-C, Herijgers P, Dubois C (2016) Functional performance and quality of life in high-risk comorbid patients undergoing transcatheter aortic valve implantation for symptomatic aortic valve stenosis. Eur Heart J Qual Care Clin Outcomes 2:184-192

8. Mehilli J, Chandrasekhar J, Sartori S, Chieffo A, Petronio AS, Lefèvre T, Presbitero P, Capranzano P, Tchetche D, Iadanza A, Sardella G, Van Mieghem NM, Meliga E, Dumonteil N, Fraccaro C, Trabattoni D, Jochheim D, Zadrozny M, Mikhail GW, Sharma S, Ferrer MC, Naber C, Kievit P, Moalem K, Baber U, Snyder C, Sharma M, Morice MC, Mehran R (2019) Impact of discharge location after transcatheter aortic valve replacement on 1-year outcomes in women: results from the WIN-TAVI Registry. Can J Cardiol 35:199-207

9. Li Z, Dawson E, Moodie J, Martin J, Bagur R, Cheng D, Kiaii B, John-Baptiste A (2019) Frailty in patients undergoing transcatheter aortic valve implantation: a protocol for a systematic review. BMJ Open 9:e024163-e024163

10. Ogawa M, Satomi-Kobayashi S, Yoshida N, Tsuboi Y, Komaki K, Wakida K, Gotake Y, Izawa KP, Sakai Y, Okada K (2019) Effects of acute phase multidisciplinary rehabilitation on unplanned readmissions after cardiac surgery. J Thorac Cardiovasc Surg. https://doi.org/10.1016/j.jtcvs.2019.11.069

11. Kleczynski P, Dziewierz A, Bagienski M, Rzeszutko L, Sorysz D, Trebacz J, Sobczynski R, Tomala M, Stapor M, Dudek D 
(2017) Impact of frailty on mortality after transcatheter aortic valve implantation. Am Heart J 185:52-58

12. Afilalo J, Lauck S, Kim DH, Lefèvre T, Piazza N, Lachapelle K, Martucci G, Lamy A, Labinaz M, Peterson MD, Arora RC, Noiseux N, Rassi A, Palacios IF, Généreux P, Lindman BR, Asgar AW, Kim CA, Trnkus A, Morais JA, Langlois Y, Rudski LG, Morin J-F, Popma JJ, Webb JG, Perrault LP (2017) Frailty in older adults undergoing aortic valve replacement: the FRAILTY-AVR Study. J Am Coll Cardiol 70:689-700

13. Otto CM, Kumbhani DJ, Alexander KP, Calhoon JH, Desai MY, Kaul S, Lee JC, Ruiz CE, Vassileva CM (2017) 2017 ACC expert consensus decision pathway for transcatheter aortic valve replacement in the management of adults with aortic stenosis: a report of the American College of cardiology task force on clinical expert consensus documents. J Am Coll Cardiol 69:1313-1346

14. Nishimura RA, Otto CM, Bonow RO, Carabello BA, Erwin JP, Guyton RA, O'Gara PT, Ruiz CE, Skubas NJ, Sorajja P, Sundt TM, Thomas JD (2014) 2014 AHA/ACC Guideline for the management of patients with valvular heart disease. A report of the American College of Cardiology/American Heart Association task force on practice guidelines. Circulation 129:e521-e643

15. Baumgartner H, Falk V, Bax JJ, De Bonis M, Hamm C, Holm PJ, Iung B, Lancellotti P, Lansac E, Rodriguez Muñoz D, Rosenhek R, Sjögren J, Tornos Mas P, Vahanian A, Walther T, Wendler O, Windecker S, Zamorano JL, Group ESD (2017) 2017 ESC/ EACTS Guidelines for the management of valvular heart disease. Eur Heart J 38:2739-2791

16. Nishimura RA, Otto CM, Bonow RO, Carabello BA, Erwin JP, Fleisher LA, Jneid H, Mack MJ, McLeod CJ, O'Gara PT, Rigolin VH, Sundt TM, Thompson A (2017) 2017 AHA/ACC focused update of the 2014 AHA/ACC Guideline for the management of patients with valvular heart disease: a report of the American College of Cardiology/American Heart Association Task Force on Clinical Practice Guidelines. Circulation 135:e1159-e1195

17. Nashef SAM, Roques F, Sharples LD, Nilsson J, Smith C, Goldstone AR, Lockowandt U (2012) EuroSCORE II $\dagger$. Eur J Cardiothorac Surg 41:734-745

18. Shahian DM, Jacobs JP, Badhwar V, Kurlansky PA, Furnary AP, Cleveland JC, Lobdell KW, Vassileva C, Wyler von Ballmoos MC, Thourani VH, Rankin JS, Edgerton JR, D'Agostino RS, Desai ND, Feng L, He X, O'Brien SM (2018) The Society of Thoracic Surgeons 2018 adult cardiac surgery risk models: part 1-background, design considerations, and model development. Ann Thorac Surg 105:1411-1418

19. O'Brien SM, Feng L, He X, Xian Y, Jacobs JP, Badhwar V, Kurlansky PA, Furnary AP, Cleveland JC, Lobdell KW, Vassileva C, Wyler von Ballmoos MC, Thourani VH, Rankin JS, Edgerton JR, D'Agostino RS, Desai ND, Edwards FH, Shahian DM (2018) The Society of Thoracic Surgeons 2018 adult cardiac surgery risk models: part 2-statistical methods and results. Ann Thorac Surg 105:1419-1428

20. Yancy CW, Jessup M, Bozkurt B, Butler J, Casey DE, Drazner MH, Fonarow GC, Geraci SA, Horwich T, Januzzi JL, Johnson MR, Kasper EK, Levy WC, Masoudi FA, McBride PE, McMurray JJV, Mitchell JE, Peterson PN, Riegel B, Sam F, Stevenson LW, Tang WHW, Tsai EJ, Wilkoff BL (2013) 2013 ACCF/ AHA guideline for the management of heart failure. Circulation 128:e240-e327

21. Yoshida N, Yamamoto H, Shinke T, Otake H, Kuroda M, Terashita D, Takahashi H, Sakaguchi K, Hirota Y, Emoto T, Amin HZ, Mizoguchi T, Hayashi T, Sasaki N, Yamashita T, Ogawa W, Hirata $\mathrm{K}$-i (2017) Impact of CD14(++)CD16(+) monocytes on plaque vulnerability in diabetic and non-diabetic patients with asymptomatic coronary artery disease: a cross-sectional study. Cardiovasc Diabetol 16:96
22. Teramoto T, Sasaki J, Ishibashi S, Birou S, Daida H, Dohi S, Egusa G, Hiro T, Hirobe K, Iida M, Kihara S, Kinoshita M, Maruyama C, Ohta T, Okamura T, Yamashita S, Yokode M, Yokote K (2014) Diagnosis of Atherosclerosis executive summary of the Japan Atherosclerosis Society (JAS) guidelines for the diagnosis and prevention of Atherosclerotic cardiovascular diseases in Japan-2012 version. J Atheroscler Thromb 21:296-298

23. Fried LP, Tangen CM, Walston J, Newman AB, Hirsch C, Gottdiener J, Seeman T, Tracy R, Kop WJ, Burke G, McBurnie MA, Cardiovascular Health Study Collaborative Research Group (2001) Frailty in older adults evidence for a phenotype. J Gerontol A Biol Sci Med Sci 56(3):M146-156

24. Ogawa M, Izawa KP, Satomi-Kobayashi S, Tsuboi Y, Komaki K, Gotake Y, Sakai Y, Tanaka H, Okita Y (2017) Impact of delirium on postoperative frailty and long term cardiovascular events after cardiac surgery. PLoS ONE 12:e0190359

25. Talbot TR (2005) Diabetes mellitus and cardiothoracic surgical site infections. Am J Infect Control 33(6):353-359

26. Mehta RL, Kellum JA, Shah SV, Molitoris BA, Ronco C, Warnock DG, Levin A, Network AKI (2007) Acute Kidney Injury Network: report of an initiative to improve outcomes in acute kidney injury. Crit Care 11:R31

27. Bäck C, Hornum M, Olsen PS, Møller CH (2019) 30-day mortality in frail patients undergoing cardiac surgery: the results of the frailty in cardiac surgery (FICS) copenhagen study. Scand Cardiovasc J 53:348-354

28. Okoh AK, Chauhan D, Kang N, Haik N, Merlo A, Cohen M, Haik B, Chen C, Russo MJ (2017) The impact of frailty status on clinical and functional outcomes after transcatheter aortic valve replacement in nonagenarians with severe aortic stenosis. Catheter Cardiovasc Interv 90:1000-1006

29. Huded CP, Huded JM, Friedman JL, Benck LR, Lindquist LA, Holly TA, Sweis RN, Ricciardi MJ, Malaisrie SC, Davidson CJ, Flaherty JD (2016) Frailty status and outcomes after transcatheter aortic valve implantation. Am J Cardiol 117:1966-1971

30. Boxer RS, Wang Z, Walsh SJ, Hager D, Kenny AM (2008) The utility of the 6-minute walk test as a measure of frailty in older adults with heart failure. Am J Geriatr Cardiol 17:7-12

31. Yamada S, Kamiya K, Kono Y (2015) Frailty may be a risk marker for adverse outcome in patients with congestive heart failure. ESC Heart Fail 2:168-170

32. Boxer R, Kleppinger A, Ahmad A, Annis K, Hager D, Kenny A (2010) The 6-minute walk is associated with frailty and predicts mortality in older adults with heart failure. Congest Heart Fail 16:208-213

33. Waite I, Deshpande R, Baghai M, Massey T, Wendler O, Greenwood S (2017) Home-based preoperative rehabilitation (prehab) to improve physical function and reduce hospital length of stay for frail patients undergoing coronary artery bypass graft and valve surgery. J Cardiothorac Surg 12:91

34. Russo N, Compostella L, Tarantini G, Setzu T, Napodano M, Bottio T, D'Onofrio A, Isabella G, Gerosa G, Iliceto S, Bellotto F (2014) Cardiac rehabilitation after transcatheter versus surgical prosthetic valve implantation for aortic stenosis in the elderly. Eur J Prev Cardiol 21:1341-1348

35. Eichler S, Salzwedel A, Reibis R, Nothroff J, Harnath A, Schikora M, Butter C, Wegscheider K, Völler H (2017) Multicomponent cardiac rehabilitation in patients after transcatheter aortic valve implantation: Predictors of functional and psychocognitive recovery. Eur J Prev Cardiol 24:257-264

36. Fauchère I, Weber D, Maier W, Altwegg L, Lüscher TF, Grünenfelder J, Nowak A, Tüller D, Genoni M, Falk V, Hermann M (2014) Rehabilitation after TAVI compared to surgical aortic valve replacement. Int J Cardiol 173:564-566

37. Tarro Genta F, Tidu M, Bouslenko Z, Bertolin F, Salvetti I, Comazzi F, Giannuzzi P (2017) Cardiac rehabilitation after 
transcatheter aortic valve implantation compared to patients after valve replacement. J Cardiovasc Med (Hagerstown) 18:114-120

38. Tamuleviciute-Prasciene E, Drulyte K, Jurenaite G, Kubilius R, Bjarnason-Wehrens B (2018) Frailty and exercise training: how to provide best care after cardiac surgery or intervention for elder patients with valvular heart disease. Biomed Res Int 2018:9849475

39. Ogawa M, Izawa PK, Kitamura A, Satomi-seimi K, Tsuboi Y, Komaki K, Sakai Y, Tanaka H, Okita Y (2017) Changes in exercise capacity and psychosocial factors in hospitalized cardiac surgery patients. Res in Cardiovasc Med 6:38-44
40. Ofori-Asenso R, Chin KL, Mazidi M, Zomer E, Ilomaki J, Zullo AR, Gasevic D, Ademi Z, Korhonen MJ, LoGiudice D, Bell JS, Liew D (2019) Global incidence of frailty and prefrailty among community-dwelling older adults: a systematic review and metaanalysis. JAMA Netw Open 2:e198398-e198398

Publisher's Note Springer Nature remains neutral with regard to jurisdictional claims in published maps and institutional affiliations. 